\title{
INTERFACIAL SHEAR STRENGTH OF RESIN PARTICLES ADDED TO CARBON FIBER/MALEIC ANHYDRIDE GRAFTED POLYPROPYLENE IN A HOT-WET ENVIRONMENT
}

\author{
HIDEAKI KATOGI \& KENICHI TAKEMURA \\ Department of Mechanical Engineering, Kanagawa University, Japan
}

\begin{abstract}
In this study, interfacial shear strength of resin particles added to carbon fiber/maleic anhydride grafted polypropylene(MAPP) in a hot-wet environment was investigated. Resin and non-resin particles added carbon fiber/MAPP were immersed in distilled water at $80^{\circ} \mathrm{C}$ for 14 days. After that, micro-debonding tests of resin and non-resin particles added carbon fiber/MAPP were conducted at room temperature. The number of resin particles in carbon fiber surface after micro debonding tests was calculated by Scanning Electron Microscope(SEM). As a result, the following conclusion was obtained: in the case of immersion for 14 days, the interfacial shear strength of resin particles added to carbon fiber/MAPP increased compared with that of non-resin particles added to carbon fiber/MAPP. From a fracture morphology observation, the total number of resin particles on the carbon fiber surface after an immersion time of 14 days was larger than that in the non-immersion case. This is because water penetrates the interfaces between carbon fiber and MAPP. However, resin particles may prevent water penetrating to the center of the specimen, because the surface area of carbon fiber was increased by the addition of resin particles. Therefore, resin particles on a carbon fiber surface were effective in increasing the interfacial shear strength of carbon fiber/MAPP in a hotwet environment.

Keywords: interfacial shear strength, carbon fiber, maleic anhydride grafted polypropylene, resin particles addition, water absorption, hot-wet environment.
\end{abstract}

\section{INTRODUCTION}

In Europe, BMW Co., Ltd. Produced the BMW i7 using carbon core technique [1]. So, the weight of the vehicle decreased $130 \mathrm{~kg}$ by carbon core technique. Carbon fiber is used as a consistent material for BMW i7. The carbon fiber has high specific stuffiness and strength. Recently, Carbon Fiber Reinforced ThermoPlastic (CFRTP) is used as stack frame of fuel cell vehicle, MIRAI [2]. The CFRTP will be applied to parts and frames of many vehicles. Therefore, many papers about molding [3]-[5] and mechanical properties [6]-[11] of CFRTP have been published. Many parts of vehicle are used under water and moisture environments. So, some research about effects of water absorption on interfacial shear strength of carbon fiber/thermoplastic have also been conducted.

Tanaka et al. [12] reported on interfacial shear strength of water absorbed carbon fiber/polyamide (polyamide 6, 12 and 66). Interfacial shear strengths of their composites after immersion for 100 hours decreased compared with those non-immersed composites. Papers about effect of water absorption on interfacial shear strength of carbon fiber/polycarbonate have also been published [13]. The interfacial shear strength of carbon fiber/polycarbonate decreased with an increase of immersion time until 400 hours.

Among thermoplastics, polypropylene is focused as matrix of CFRTP for vehicle. Generally, polypropylene is modified by maleic anhydride because interfacial adhesion between carbon fiber and polypropylene is low. In addition, surface treatment of carbon fiber is investigated for improvement of interfacial adhesion between fiber and resin. 
Meng et al. [14] reported about inter-surface performance of oxidation treated carbon fiber/epoxy. The carbon fiber surface after oxidation treatment became uneven. Interfacial shear strength of carbon fiber/epoxy resin increased $13 \%$ by oxidation treatment $\left(\mathrm{H}_{2} \mathrm{O}_{2}\right.$ $3 \mathrm{ml}$ ). Hara et al. [15] reported on interfacial shear strength of resin particle added carbon fiber/maleic anhydride grafted polypropylene(MAPP). The interfacial shear strength of carbon fiber/MAPP increased by resin particle addition.

Parts and frames of vehicle are used under high environmental (ambient) temperature. In Japan, the maximum temperature of dashboard in vehicle in July was about $80^{\circ} \mathrm{C}$ [16]. So, interfacial shear strength of carbon fiber/MAPP under hot-wet environment can be increased by surface treatment with resin particles addition. However, there are few papers about interfacial shear strength of composite using resin particle added carbon fiber under hot-wet environment.

This study investigated the interfacial shear strength of resin particle added carbon fiber/MAPP under hot-wet environment.

\section{SPECIMENS}

Resin and non-resin particles added to carbon fiber (Sekisui Chemical Co., Ltd.) were used as reinforcement. MAPP (UMEX 1001, Sanyo Chemical Industries Co., Ltd.) was used as matrix. The concentration of MAPP was $5 \%$. Fig. 1 shows schematic drawing of specimen for micro debonding test. Embedded length of resin droplet was from $0.1 \mathrm{~mm}$ to $0.3 \mathrm{~mm}$.

\section{TESTING METHODS}

\subsection{Water absorption test}

Water absorption tests of resin and non-resin particles added carbon fiber/MAPP were conducted in distilled water. The environmental temperature of the water absorption test was $80^{\circ} \mathrm{C}$. The maximum immersion time was 14 days.

\subsection{Micro debonding test}

Micro debonding tests of resin and non-resin particles added carbon fiber/MAPP were conducted before and after water absorption test. The environmental temperature was room temperature. The crosshead speed of micro debonding test was $0.1 \mathrm{~mm} / \mathrm{min}$. The interfacial

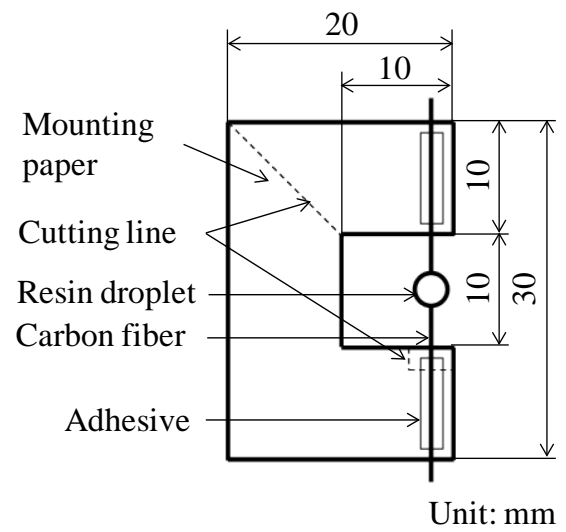

Figure 1: Schamatic drawing of specimen. 
shear strength $\tau$ is obtained by following eqn (1).

$$
\tau=\frac{F_{\max }}{\pi \cdot d \cdot L},
$$

where, $d$ is diameter of carbon fiber, $L$ is embedded length and $F_{\max }$ is maximum load.

\subsection{Fracture morphology observation}

Before and after immersion, fracture morphologies of resin and non-resin particle added carbon fiber/MAPP were observed by Scanning Electron Microscope(SEM) (SU-8010, Hitachi High-technologies Co., Ltd.).

\subsection{Number of resin particle measurement}

Form fracture morphology observation, diameter and number of resin particles on carbon fiber surface at five areas $(10 \mu \mathrm{m}$ each) were measured in fiber direction. After that, the average value of number of resin particles was calculated.

\section{RESULTS AND DISCUSSION}

\subsection{Interfacial shear strength of carbon fiber/MAPP after immersion}

Fig. 2 shows interfacial shear strength of resin and non-resin particles added carbon fiber/MAPP before and after immersion. In case of non-immersion, the interfacial shear strength of resin particles added carbon fiber/MAPP almost did not change, compared with that of non-resin particles added carbon fiber/MAPP. The interfacial shear strengths of resin and non-resin particles added carbon fiber/MAPP after immersion for 7 days decreased $67 \%$ and $58 \%$, respectively, compared with those of resin and non-resin particles added carbon fiber/MAPP before immersion. Then interfacial shear strength of non-resin particles added carbon fiber/MAPP gently decreased with an increase of immersion time. But, interfacial shear strength of resin particles added carbon fiber/MAPP slightly increased with an increase of immersion time. In case of immersion, the interfacial shear strength of resin particles added carbon fiber/MAPP increased, compared with that of non-resin particles added carbon fiber/MAPP. So, the interfacial shear strength of carbon fiber/MAPP under hot-wet environment was affected by resin particle addition.

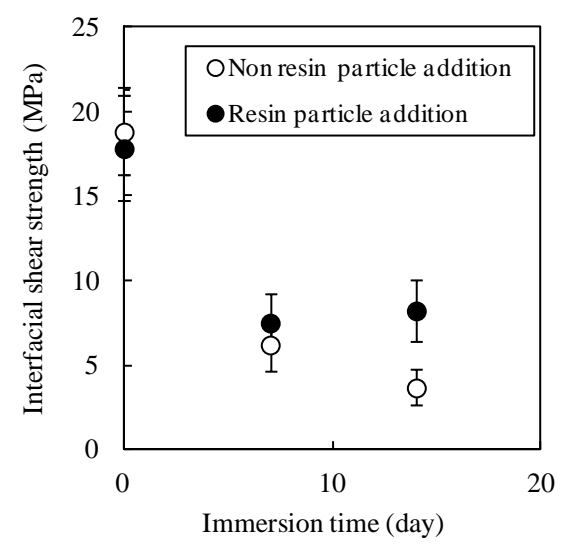

Figure 2: Interfacial shear strength of resin and non-resin particles added carbon fiber/MAPP before and after immersion. 
Figs 3 and 4 show fracture morphologies of resin and non-resin particles added carbon fiber/MAPP before and after immersion. In case of non-resin particles added carbon fiber/MAPP, MAPP on carbon fiber surface almost did not found except for meniscus area. In case of resin particles added carbon fiber/MAPP, resin particles on carbon fiber surface was found. Those were because that water penetrated to interface between carbon fiber surface and MAPP with an increase of immersion time.

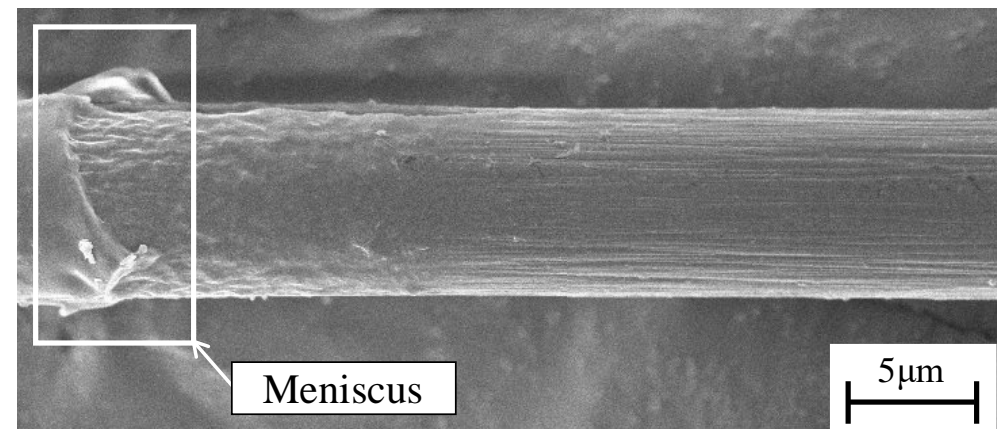

(a)

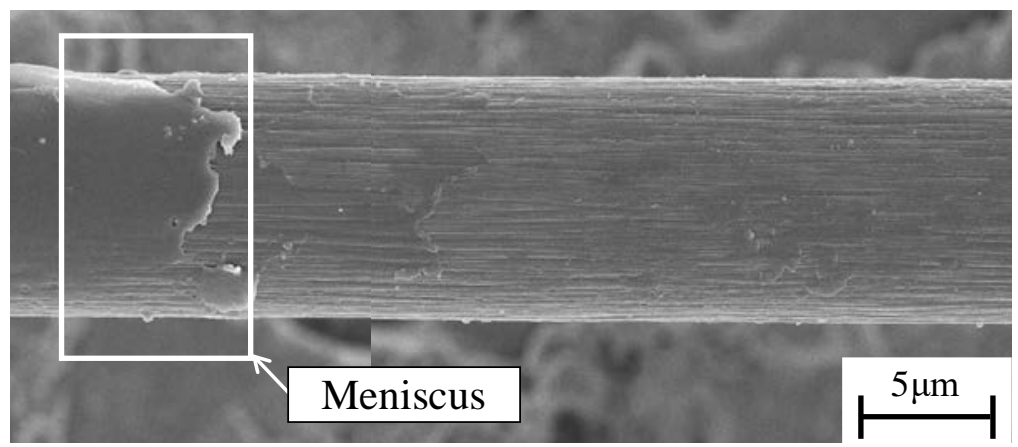

(b)

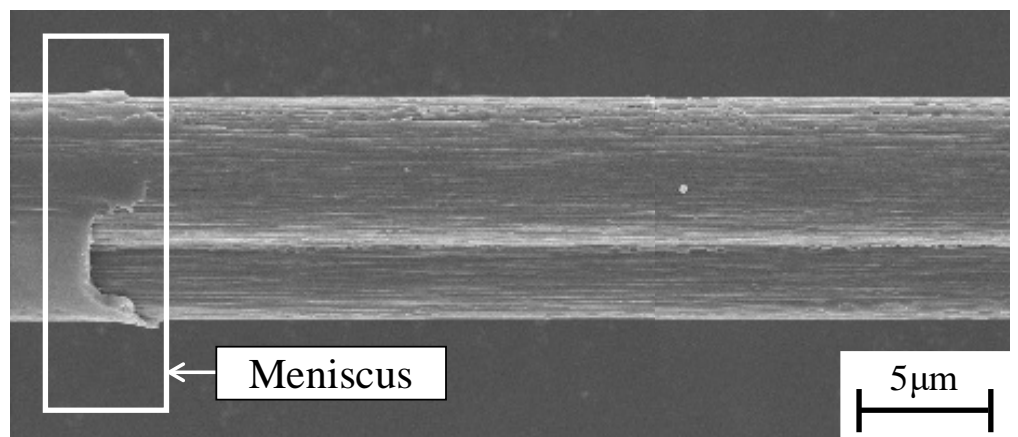

(c)

Figure 3: Fracture morphologies on non-resin particles added carbon fiber/MAPP before and after immersion. (a) Non-immersion; (b) Immersion time 7 days; (c) Immersion time 14 days. 


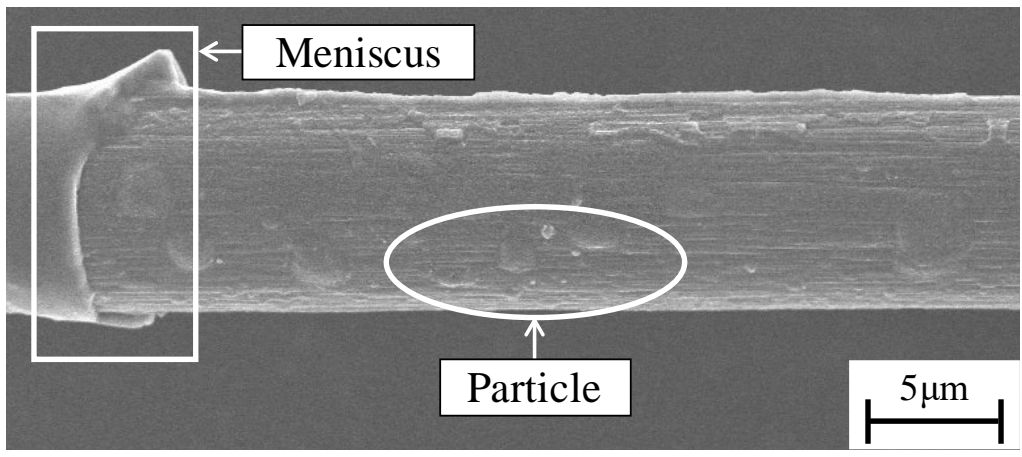

(a)

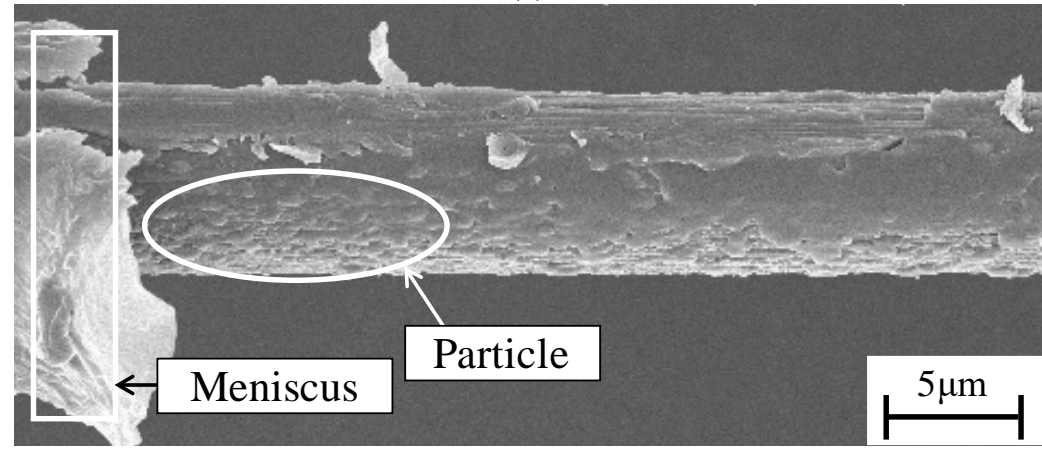

(b)

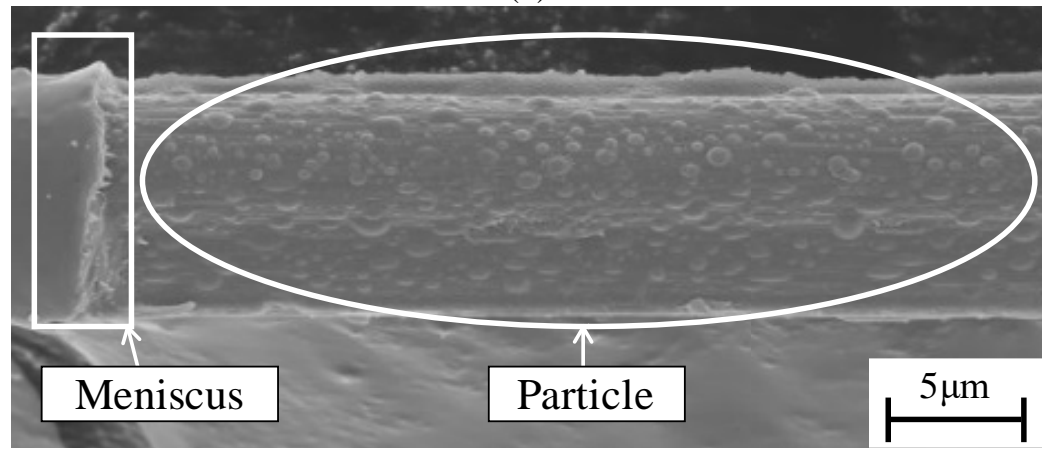

(c)

Figure 4: Fracture morphologies of resin particle added carbon fiber/MAPP before and after immersion. (a) Non-immersion; (b) Immersion time 7 days; (c) Immersion time 14 days.

4.2 Number of resin particles measurement of resin particles added carbon fiber/MAPP

Fig. 5 shows number of resin particle on carbon fiber surface before and after micro debonding test. And Fig. 6 shows number of resin particle on carbon fiber surface after immersion. In case of all conditions, $0.5 \mu \mathrm{m}$ size resin particles on carbon fiber surface 
were mainly found. Resin particles at more than $2.0 \mu \mathrm{m}$ size on carbon fiber surface almost were not found before and after immersion.

Fig. 7 shows total number of resin particle on carbon fiber surface. Total number of resin particle on carbon fiber surface after micro debonding test decreased $83 \%$, compared with that of carbon fiber surface before micro debonding test. Total number of resin particle on carbon fiber surface increased with an increase of immersion time. Total number of resin particle on carbon fiber surface after immersion for 14 days greatly increased, compared with that of immersion for 8 days case. Those are because that water penetrates to interface between carbon fiber surface and MAPP. However, resin particles may prevent water penetration to the center of specimen because surface area of carbon fiber was increased by resin particles addition (see Fig. 8). Therefore, resin particles on carbon fiber surface were effective in increase of interfacial shear strength of carbon fiber/MAPP under hot-wet environment.

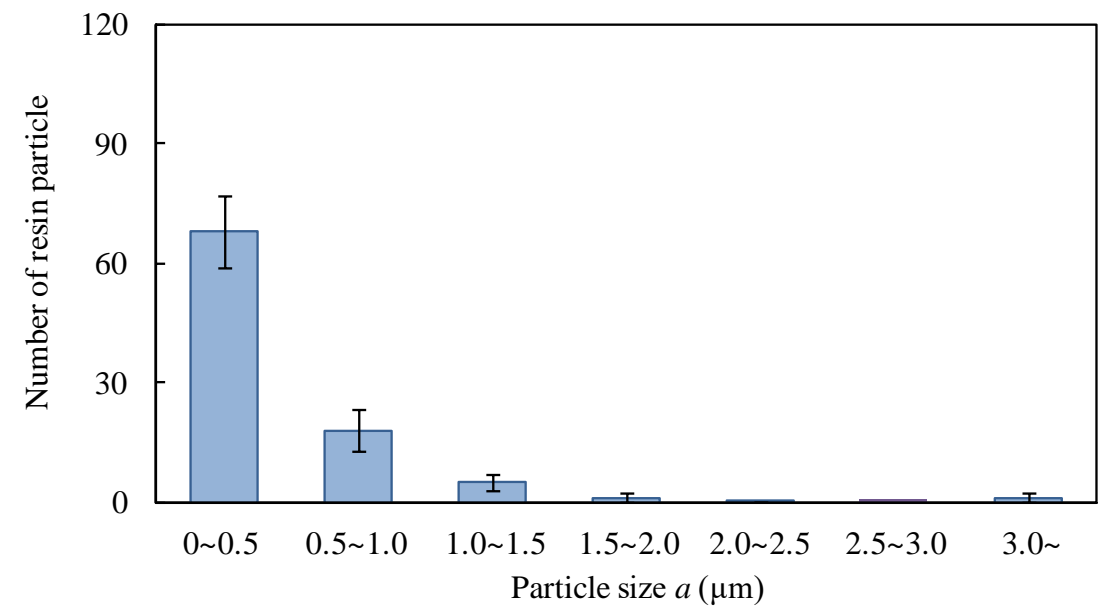

(a)

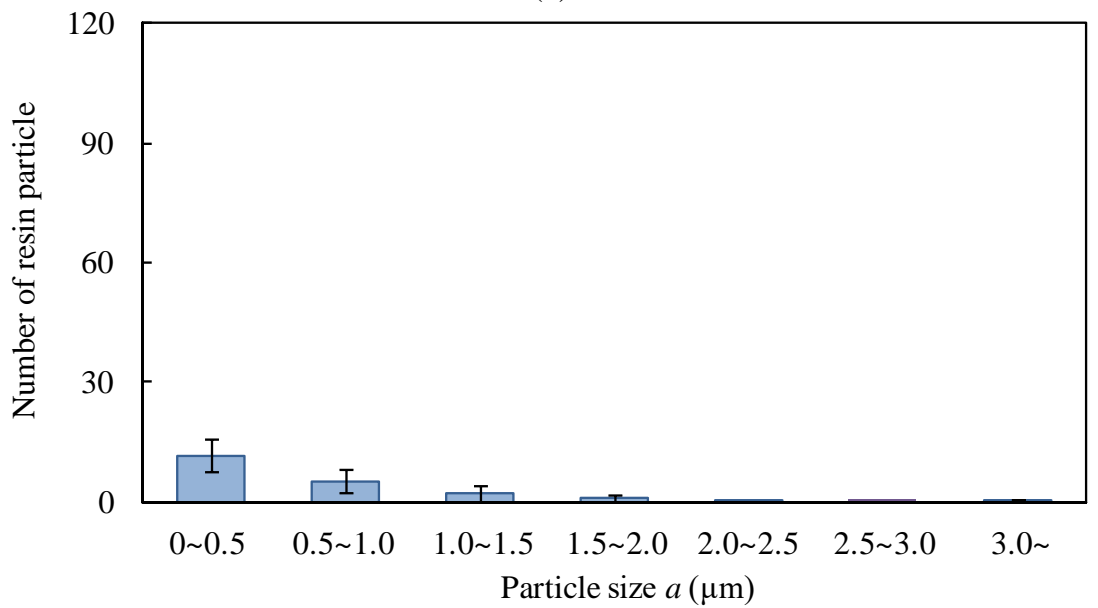

(b)

Figure 5: Number of resin particle on carbon fiber surface. (a) Before micro debonding test (virgin); (b) After micro debonding test (non-immersion). 


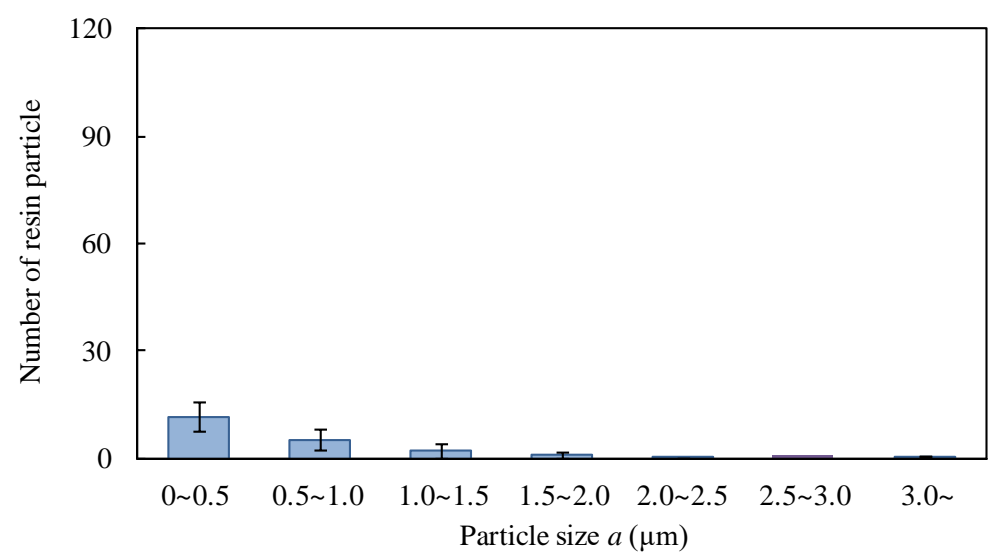

(a)

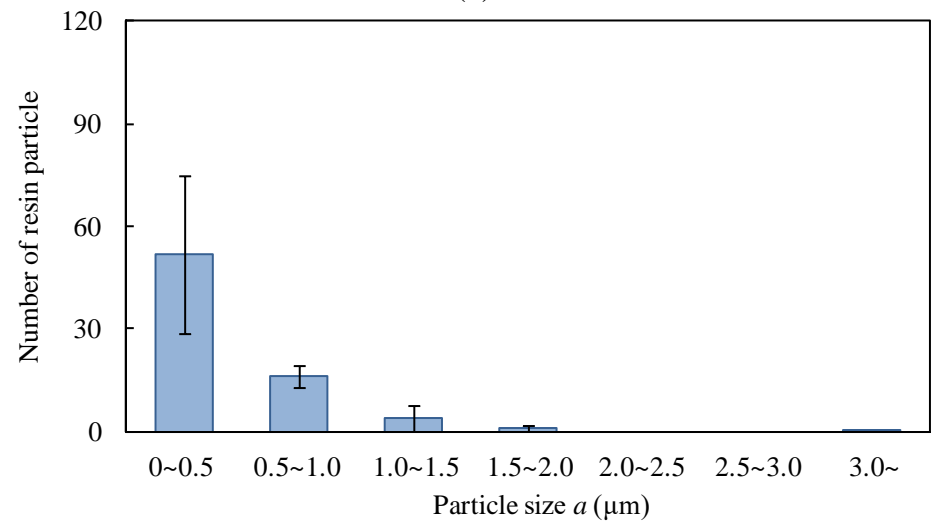

(b)

Figure 6: Number of resin particle on carbon fiber surface after immersion. (a) Immersion time 7 days; (b) Immersion time 14 days.

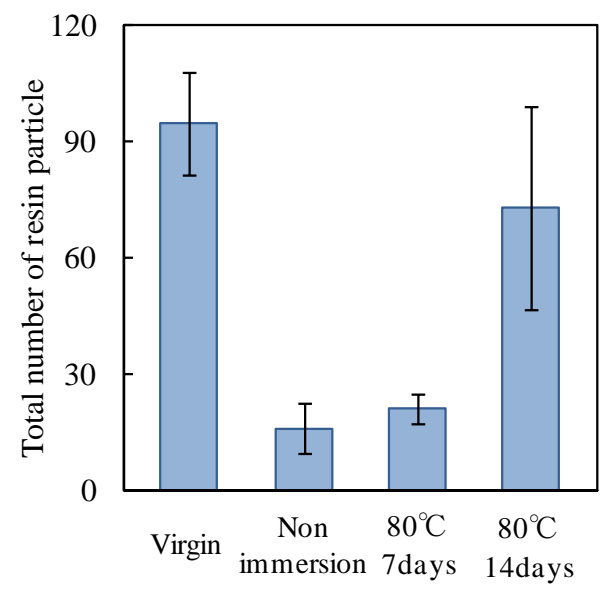

Figure 7: Total number of resin particle on carbon fiber surface. 


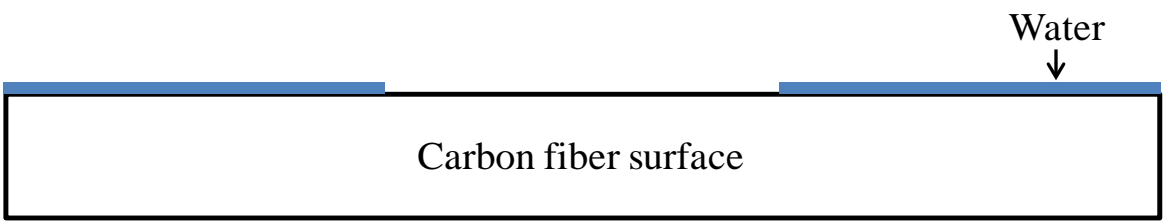

(a) Non-resin particle addition.

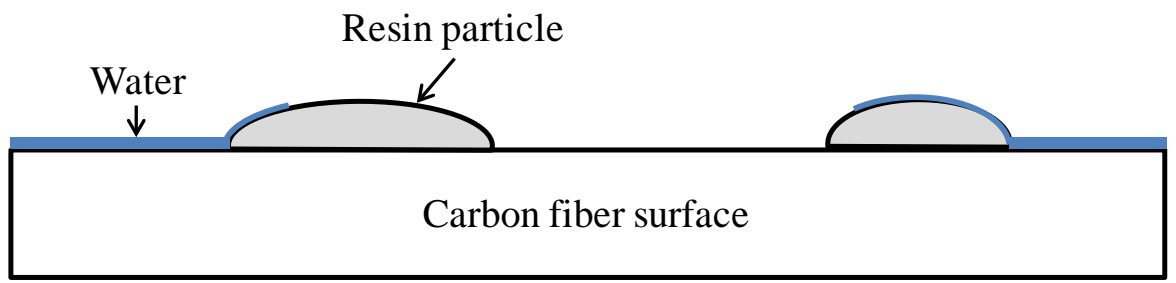

(b) Resin particle addition.

Figure 8: Water penetration on carbon fiber surface under hot-wet environment.

\section{CONCLUSION}

In this study, the interfacial shear strength of resin particles added carbon fiber/maleic anhydride grafted polypropylene under hot-wet environment was investigated. As a result, following conclusions are obtained.

In case of immersion by 14 days, the interfacial shear strength of resin particles added carbon fiber/maleic anhydride grafted polypropylene increased compared with that of nonresin particles added carbon fiber/maleic anhydride grafted polypropylene. From fracture morphology observation, $0.5 \mu \mathrm{m}$ size resin particles on carbon fiber surface were mainly found. And, total number of resin particle on carbon fiber surface increased with an increase of immersion time. Resin particles may prevent water penetration to the center of specimen because surface area of carbon fiber was increased by resin particles addition. Therefore, resin particles on carbon fiber surface were effective in increase of interfacial shear strength of carbon fiber/maleic anhydride grafted polypropylene under hotwet environment.

\section{ACKNOWLEDGEMENTS}

We would like to thank Mr. M. Nakamura (Sekisui Chemical Co., Ltd.) for supplying resin particle added carbon fiber.

\section{REFERENCES}

[1] Nikkei Business Publications, Inc., Online. http://techon.nikkeibp.co.jp/atcl/car/15/ 100900013/ 101100006/.

[2] Toray Co., Ltd., Online. http://www.toray.com/news/carbon/detail.html?key= D144E85F1C996 C5149257D950007222B.

[3] Tanaka, K., Nakatsuka, J., Matsuura, Y., Ueda, T. \& Katayama, T., CFRTP pipe molding process using high-frequency direct resistance heating. WIT Transactions on Engineering Sciences, 90, pp. 217-224, 2015.

[4] Tanaka, K., Yamada, T., Moriito, K. \& Katayama, T., The effect of molding pressure on the mechanical properties of CFRTP using paper-type intermediate material. WIT Transactions on the Built Environment, 166, pp. 307-315, 2016. 
[5] Tanaka, K., Kondo, Y. \& Katayama, T., Effect of mold temperature on interfacial welded strength and outer shell laminate strength of CF/PA6 composites manufactured by press and injection hybrid molding. WIT Transactions on the Built Environment, 166, pp. 317-327, 2016.

[6] Katouzian, M., Bruller, O.S. \& Horoschenkoff, A., On the effect of temperature on the creep behavior of neat and carbon fiber reinforced PEEK and epoxy resin. Journal of Composite Materials, 29, pp. 372-387, 1995.

[7] Arao, Y., Yumitori, S., Suzuki, H., Tanaka, T., Tanaka, K. \& Katayama, T., Mechanical properties of injection-molded carbon fiber/polypropylene composites hybridized with nanofillers. Composites Part A: Applied Science and Manufacturing, 55, pp. 19-26, 2013.

[8] Takemura, K. \& Katogi, H., Interfacial shear strength of carbon fiber reinforced polypropylene. Key Engineering Materials, 525-526, pp. 49-52, 2013.

[9] Kim, J.W. \& Lee, J.S., Influence of interleaved films on the mechanical properties of carbon fiber fabric/polypropylene thermoplastic composites. Materials, 9, pp. 344356, 2016.

[10] Tanaka, K., Ohno, K. \& Katayama, T., Effect of PP modification and processing time on fiber/matrix interfacial strength for carbon fiber reinforced polypropylene. WIT Transactions on the Built Environment, 166, pp. 329-334, 2016.

[11] Do, V.T., Nguyen-Tran, H.D. \& Chun D.M., Effect of polypropylene on the mechanical properties and water absorption of carbon-fiber-reinforced polyamide6/polypropylene composite. Composite structures, 150, pp. 240-245, 2016.

[12] Tanaka, K., Mizuno, S., Honda, H., Katayama, T. \& Enoki, S., Effect of water absorption on the mechanical properties of carbon fiber/polyamide composites. Journal of Solid Mechanics and Materials Engineering, 7, pp. 520-529, 2013.

[13] Tanaka, K., Fukushima, Y., Kashihara, K. \& Katayama, T., Effect of water absorption on the mechanical properties of continuous carbon fibre reinforced polycarbonate composites. WIT Transactions on the Built Environment , 112, pp. 153162, 2010.

[14] Meng, L., Fan, D., Zhang, C., Jiang, Z. \& Huang, Y., The Effect of oxidation treatment with supercritical water/hydrogen peroxide system on intersurface performance for polyacrylonitrile - based carbon fibers. Applied Surface Science, 273, pp. 167-172, 2013.

[15] Hara, T., Katogi, H. \& Takemura, K., Effect of water absorption and resin particle on interfacial shear strength of CF/MAPP. Advanced Materials Research, 1110, pp. 2326, 2015.

[16] Tanabe, S., Wada, R., Haneda, M., Yamada, M., Nagayama, H. \& Oi, H., Solarheated car cabin: part 2 increased fuel economy for solar heat load reduction. Technical paper of annual meeting the Society of Heating, Air-Conditioning and Sanitary Engineering of Japan, pp. 941-944, 2005 (in Japanese). 